\title{
Registration Specialist
}

National Cancer Institute

\section{Source}

National Cancer Institute. Registration Specialist. NCI Thesaurus. Code C54632.

A user who, on behalf of a sponsor, will manage and process the Investigator registrations. 